\title{
(t)
}

\section{O ESTADO NEOLIBERAL FACE À COVID-19: O FINANCIAMENTO DE POLÍTICAS SOCIAIS}

\author{
The neoliberal state in the face of the COVID-19: the social policy funding \\ Diego de Oliveira Souza* \\ http://orcid.org/0000-0002-1103-5474
}

\section{RESUMO}

O objetivo desse ensaio é realizar uma reflexão sobre o Estado em face da pandemia de COVID-19. Como particularidade analítica, toma-se o caso do financiamento de políticas sociais (sobretudo, na saúde) no contexto do neoliberalismo. Busca-se os fundamentos teórico-analíticos na concepção de Estado de Karl Marx e Friedrich Engels, dialogando com Antonio Gramsci, Ernest Mandel e István Mészáros. Critica-se, brevemente, a concepção jusnaturalista de John Locke e Adam Smith para, em seguida, desenvolver a crítica ao neoliberalismo. A partir de bibliografia atual e de documentos, demonstra-se as consequências do neoliberalismo para as políticas públicas, sobretudo com o processo de subfinanciamento. A pandemia de COVID-19 comparece nesse mosaico social fazendo com que essa questão fique ainda mais evidente, uma vez que o seu enfrentamento é limitado pela capacidade dos sistemas públicos de saúde e suas sequelas se agravam ante um conjunto de políticas sociais fragilizadas.

\section{PALAVRAS-CHAVE}

COVID-19; Estado; Financiamento de políticas sociais; Saúde Pública

\section{ABSTRACT}

The aim of this essay is to reflect on the State in the face of the COVID-19 pandemic. In particular, the case of public policy funding (especially in health) is analyzed in the context of neoliberalism. The theoretical analysis is based on the concept of the State of Karl Mar and Friedrich Engels, in dialogue with Antonio Gramsci, Ernest Mandel and István Mészáros. We briefly criticize the jusnaturalist conception of John Locke and Adam Smith and then developed the critique of neoliberalism. From current literature and documents, the consequences of neoliberalism for public policies are demonstrated, especially with the process of underfunding. The COVID-19 pandemic appears in this social mosaic making this issue even more evident, while its confrontation is limited by the capacity of the public health systems and its sequelae worsen in the face of a set of weakened social policies.

\section{KEYWORDS}

COVID-19; State; Social policy funding; Public Health

\footnotetext{
* Enfermeiro. Doutor em Serviço Social. Professor da Universidade Federal de Alagoas. (Ufal, Arapiraca, Brasil). Av. Manoel Severino Barbosa, s/n, Bairro Bom Sucesso, Arapiraca (AL), CEP 57309-005. E-mail: diego.souza@arapiraca.ufal.br.
}

DOI 10.22422/temporalis.2021v21n41p190-204

○ A(s) Autora(s)/O(s) Autor(es). 2019 Acesso Aberto Esta obra está licenciada sob os termos da Licença Creative Commons Atribuição 4.0 Internacional (https://creativecommons.org/licenses/by/4.0/deed.pt_BR), que permite copiar e redistribuir o material em qualquer suporte ou formato, bem como adaptar, transformar e criar a partir deste material para qualquer fim, mesmo que comercial. O licenciante não pode revogar estes direitos desde que você respeite os termos da licença. 


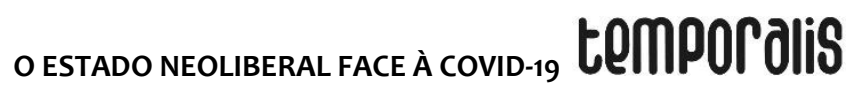

\section{INTRODUÇÃO}

m 2020, em poucos meses, a pandemia de COVID-19 alterou a vida cotidiana em nível mundial. Podemos dizer que seu caráter pandêmico não se restringe mais ao aspecto epidemiológico, de saúde, consoante comumente o termo pandemia é empregado, mas diz respeito a um abalo geral da rotina estabelecida no capitalismo contemporâneo. Obviamente, essa dinâmica não isentou o Estado, ao contrário disso, conferiu destaque internacional a cada passo que os governos à frente dos Estados-nação foram dando no enfrentamento da pandemia.

As polêmicas sobre os limites do neoliberalismo assumiram relevo no debate, com questionamentos sobre a capacidade dos sistemas de saúde e da seguridade social como um todo; a suposta disputa entre saúde e economia; e, inclusive, sobre os limites das medidas de distanciamento social (com fechamento da maioria dos serviços e indústrias) para a prevenção de novos casos e óbitos, com, consequentemente, injeção de recursos públicos na seguridade social, ciência e tecnologia.

Quais as reverberações da atual conformação estatal, em seus aspectos predominantes mundialmente, no curso da pandemia? Como a pandemia, por sua vez, reverbera nessa dinâmica estatal? A relação entre neoliberalismo e saúde, ora mediada pela pandemia, é evento pontual e fugaz, ou constitui uma expressão eminente de um processo históricosocial mais amplo? Com o objetivo de tecer considerações reflexivas sobre o Estado ante a pandemia de COVID-19, esse texto busca contribuir para a resolução dessas questões.

Esclarecemos que tomamos, como mediação particular de análise, a questão do financiamento de políticas sociais, sobretudo na saúde, trazendo os casos de alguns países, antes e durante a pandemia. Para tanto, recuperamos os fundamentos teóricos da concepção materialista-histórica de Estado, a partir de Karl Marx e Friedrich Engels, mas dialogando com outros marxistas, a exemplo de Antonio Gramsci, Ernest Mandel e István Mészáros. Na sequência, demarcamos o que seja o neoliberalismo (recuperando desde as premissas jusnaturalistas), tecendo, posteriormente, algumas considerações críticas. Por fim, trazemos dados sobre o financiamento das políticas sociais, com ênfase na saúde, a partir de bibliografia correlata e de documentos oficiais, analisando-os a partir dos princípios teóricos apresentados nas seções anteriores.

\section{CONSIDERAÇÕES MARXISTAS SOBRE O ESTADO}

Apreender em que consiste o Estado é passo decisivo para a análise da sua fase neoliberal e, consequentemente, das contradições engendradas ante a pandemia de COVID-19. Partimos de Marx e Engels (2010) no sentido de refutar qualquer caráter de neutralidade ou imparcialidade imputado ao Estado, concebendo-o, ao contrário disso, enquanto instituição dialeticamente articulada à luta de classes, tendenciosa aos interesses da classe dominante.

Não estamos querendo dizer, com isso, que o Estado seja imune às tensões consubstanciadas no movimento operário ou em outros movimentos sociais. Gramsci 
(2012) contribui para dar visibilidade a essa dimensão política a partir da luta de classes, na perspectiva de organização de setores da sociedade civil, sobremodo, da classe trabalhadora. A concepção de Estado ampliado permite entender a sociedade civil como arena privilegiada do curso da luta de classes e seus rebatimentos sobre aquilo que Gramsci (2012) chamou de sociedade política, o Estado em sentido estrito.

Em que pese a importância de reconhecer que o Estado (para nós, sempre em sentido estrito) tem sua dinâmica susceptível às contingências gestadas na organização política da classe trabalhadora, entendemos que a noção de Estado ampliado se afasta, em alguma medida, daquela de Marx e Engels (2010). Para Gramsci, o Estado está situado na dimensão superestrutural da sociedade, o que abriu caminho para interpretações posteriores que superestimaram essa dimensão ou a ela conferiram autonomia diante da dimensão econômica.

A nosso ver, Mészáros (2009) avança na resolução desse equívoco. Para o filósofo húngaro, o Estado é ele mesmo uma estrutura particular das sociedades de classes, contendo, na sua dinâmica, suas próprias facetas estrutural e superestrutural. Na verdade, o avanço de Mészáros consiste em realizar uma digressão precisa à obra de Marx e Engels e, a partir dela, contribuir para a resolução dos enigmas contemporâneos. Engels (2010) já havia traduzido o pensamento marxiano em $A$ origem da propriedade privada, da família $e$ do Estado, quando demonstrou a natureza indissociável do Estado para com as sociedades de classes, constituídas em torno da apropriação privada da riqueza produzida socialmente.

Mészáros (2009) ratifica esse argumento, destacando que o Estado é uma estrutura de controle político que, por determinação reflexiva à exploração e à dominação de classe, concretiza a dicotomia entre as esferas econômica e política, quando os que dominam aquela esfera não precisam, necessariamente, exercer o poder nesta. O resultado dessa dicotomia é uma forma de comando político hierarquicamente sobreposta aos diversos segmentos da sociedade civil, embora, na sua essência, a ela umbilicalmente articulada. Portanto, trata-se de uma instituição que, na sua forma burguesa, na concepção de Mészáros (2009), complementa o capital, não se confunde com ele, mas nasce em conjunção ao mesmo. Por isso,

\begin{abstract}
Como o Estado nasceu da necessidade de conter o antagonismo das classes, e como, ao mesmo tempo, nasceu em meio ao conflito delas, é, por regra o Estado da classe mais poderosa, da classe economicamente dominante, classe que, por intermédio dele, se converte também em classe politicamente dominante e adquire novos meios para a repressão e exploração da classe oprimida. Assim, o Estado antigo foi, sobretudo, o Estado dos senhores de escravos para manter os escravos subjugados; o Estado feudal foi o órgão de que se valeu a nobreza para manter a sujeição dos servos e camponeses dependentes; e o moderno Estado representativo é o instrumento de que se serve o capital para explorar o trabalho assalariado (ENGELS, 2010, p. 215-216).
\end{abstract}

Isto é, em cada modo de produção, em conjunção à forma particular de luta de classes que Ihe subjaz, engendra-se uma forma particular de Estado que, na sua faceta política, consubstancia a dominação de classe. Essa maneira de conceber o Estado refuta as interpretações marxista que explicam o surgimento do Estado como um produto linear (a 
partir) da luta de classes. Em vez disso, é preciso entender tanto o Estado quanto a luta de classes como elementos estruturalmente constituintes das sociedades de classe, surgindo em conjunção histórica e, não, em uma relação mecânica de causa-efeito.

O caráter estrutural do Estado também foi destacado por Mandel (1982), quando analisa a fase do capitalismo que ele chamou de capitalismo tardio. Chamamos a atenção para que não se confunda a denominação que Mandel atribui ao capitalismo monopolista com as teses que classificam os países economicamente atrasados como sendo capitalistas tardios ou retardatários. Mandel (1982) está se referindo à fase última do capitalismo na história (até então) e, ao fazê-lo, demonstra a hipertrofia do seu caráter estrutural, de cunho econômico mesmo. Para o autor, ao Estado cabem funções estruturais, oferecendo o suporte necessário às atividades dos vários capitalistas, em especial, do grande capital.

Em que pese algumas diferenças importantes entre Mészáros e Mandel, no quesito acima apontado, existe uma aproximação. É essa concepção de Estado que levamos à análise do neoliberalismo na seção seguinte.

\section{O ESTADO NA SUA FACE NEOLIBERAL}

Inicialmente, é preciso esclarecer que não existe absoluta identidade entre o liberalismo clássico e o neoliberalismo, apesar de o segundo representar o aprofundamento da tendência que, nas suas linhas fundamentais, está contida no primeiro, qual seja: a ideia de que a ação estatal não pode ser obstáculo à efetivação da liberdade individual. A limitação da dinâmica estatal, nessa concepção, deve ter em vista o que alguns autores jusnaturalistas, sobretudo John Locke, chamaram de direitos naturais (TEIXEIRA, 1998).

Esses direitos, em suma, são três: direito à vida, à liberdade e à propriedade. O direito à propriedade assume relevo na concepção jusnaturalista, porquanto seja o eixo movente do tripé. Vejamos: o direito à vida, exercido plenamente, deve ser direcionado a uma vida mais confortável, para o que a premissa básica seria a propriedade privada. $\mathrm{O}$ direito à liberdade deve ser, sobremaneira, a liberdade jurídico-política que dissolva as relações de servidão que eram, na transição do antigo regime feudal para o capitalismo, um obstáculo à consubstanciação de uma massa de compradores e vendedores de mercadorias. Para Locke (1978), isso se justificaria devido ao fato de o indivíduo preceder ao Estado e à sociedade civil, o que explicaria a questão de a verdadeira natureza humana ser individualista. Por essa razão, os homens teriam todo o direito de buscar a satisfação de suas necessidades individuais, por meio da apropriação privada. Partindo desse pressuposto, são os indivíduos, na sua natureza individualista, que concebem e soerguem o Estado e a sociedade civil, seguindo com a escolha de alguma forma de governo que deve, em respeito à essência humana, proteger a propriedade privada. Essa premissa é a base do liberalismo clássico e, em alguma medida, é resgata no neoliberalismo.

Adam Smith parte de pressupostos semelhantes ao afirmar que, na ocasião de Estados interventores, põe-se obstáculos à livre operação da lei do valor, ou seja, à generalizada compra e venda de mercadorias que, então, seria responsável pelo equilíbrio e a viabilidade da vida social. Para tal, o direito à propriedade privada seria condição peremptória, sendo justa e necessária a corrida individual pelo mérito de possuí-la. Assim, compradores e 
vendedores forjariam uma cadeia de relações recíprocas da qual emergiria a coesão da sociedade. O mercado atuaria como uma mão invisível, uma vez que cada indivíduo, em seu esforço na busca por ampliar suas propriedades, permitiria a ampliação da renda geral da sociedade e, com isso, impulsionaria o desenvolvimento (SMITH, 1988).

Marx se contrapôs, radicalmente, a Smith, revelando que o mercado consistiria na arena na qual se efetiva o distanciamento entre a satisfação das necessidades humanas e as necessidades do mercado. Nessa arena, nenhuma coesão social seria possível, ao contrário, ocorreria a alienação entre o trabalhador e o seu trabalho, gerando um abismo cada vez maior entre proprietários dos meios de produção (capitalistas) e aqueles que apenas possuem a sua força de trabalho (o proletariado) (MARX, 1988).

O liberalismo clássico, todavia, para justificar a suposta insuperabilidade do capitalismo, tratou de atribuir ao mercado o status de lócus da verdadeira natureza humana, quando o indivíduo poderia expressar seu autêntico ethos de forma livre, sem os empecilhos, por exemplo, provenientes da esfera estatal. Esse ideal foi predominante durante o capitalismo clássico, concorrencial, até o final do século XIX. Entretanto, no início do século XX, deparou com os limites da sua dinâmica, levada às últimas consequências, cujo resultado foram as duas Guerras Mundiais.

Cumpre lembrar que, no bojo do curso do capitalismo concorrencial, a crise de 1929 explicitou a disrupção daquele tipo de relação entre Estado e economia. Consoante Netto (2012), houve desemprego em massa, bancarrota generalizada e queda dos preços no mercado, obrigando o Estado a abandonar sua posição de mero vigia da economia para assumir o papel de salvador do sistema. A principal estratégia para tal empreitada foram as políticas de apoio direto ao processo de acumulação de capital, travestidas de ações compensatórias de ajuda aos excluídos do mercado por meio de políticas sociais características do que ficou conhecido como Welfare State (Estado de Bem-Estar Social). Essa nova articulação Estado-economia vigorou em alguns países de capitalismo avançado, sobretudo na Europa ocidental e nórdica, marcando o período denominado de anos dourados, devido às altas taxas de lucro.

O Estado de Bem-Estar Social funcionou para a dinâmica de acumulação por três décadas, especialmente agindo na contenção da tendência decrescente da taxa de lucros. Porém, gerou as condições para a sua própria ruína, em face dos limites absolutos do capital (MÉSZÁROS, 2009). A estratégia de estimular o consumo por meio da estruturação de serviços públicos ocasionou uma pletora de acumulação, o que travou o mercado financeiro e evidenciou as limitações produtivas do binômio taylorismo/fordismo, mesmo na perspectiva dos capitalistas. De imediato, o liberalismo saiu das sombras como resposta para a bancarrota, mas agora, obviamente, deparando com novas contingências (TEIXEIRA, 1998).

Podemos afirmar que o neoliberalismo emerge desse contexto, trazendo ideais liberais, sendo que dinamizando-as na contemporaneidade. Enquanto movimento teórico, pairava desde a década de 1940, questionando e tensionando o Welfare State, sobretudo com os debates de Frederick Hayek, na defesa da liberdade econômica e política como lastro para a prosperidade. Foi com a crise dos anos de 1970 que o neoliberalismo encontrou as 
condições objetivas que permitiriam a sua efetivação social, desde os países de capitalismo avançado até os dependentes (TEIXEIRA, 1998).

Com o neoliberalismo, mantém-se a premissa do mercado enquanto limitador do espaço do Estado, mas com algumas diferenças, uma vez que a intervenção estatal é cada vez mais requisitada para a provisão da estrutura necessária ao desenvolvimento das relações mercantis, assim como na garantia de algumas políticas de renda mínima, porquanto seja preciso manter alguma ordem social para a livre concorrência se desenvolver sem grandes contestações.

A despeito dessas políticas sem tanto alcance, houve a fragmentação, a redução e a privatização dos sistemas de seguridade social, com a venda de estatais e incentivos à migração de grandes empresas à conquista de novos nichos. Como adverte Netto (2012), não se trata do mero retorno ao liberalismo clássico:

[... ] o Estado mínimo que os neoliberais advogam não é um retorno puro e simples ao 'Estado guarda-noturno' que é o seu ideal - são forçados a reconhecer-lhe um pouco mais que a mera guarda da propriedade: por um lado, combatem os sistemas de segurança e previdência social; por outro, toleram alguma ação estatal em face do pauperismo (NETTO, 2012, p. 87, grifos do autor).

Então, a função econômica do Estado é hipertrofiada a partir da década de 1970, marcando a consolidação do neoliberalismo, em especial nos países de capitalismo avançado. Porém, antes de tomar dinâmica contundente nos países ricos, houve uma espécie de ensaio no universo do capitalismo dependente, tendo em vista que a experiência do governo de Augusto Pinochet, no Chile, já mostrava traços do neoliberalismo, embora com caráter heterônimo e conduzida pela coação de um Estado ditatorial. De 1979 para 1980, constituíram-se as experiências iniciais mais emblemáticas, com Margaret Thacther no Reino Unido e Ronald Reagan nos Estados Unidos da América (E.U.A.). O metiê estatal passa a incluir medidas como a ampliação da emissão monetária e sua perdulária elevação das taxas de juros, isenção dos impostos do grande capital, coibição do sindicalismo e dos movimentos sociais, desemprego massivo, desfinanciamento de políticas sociais e seguidas privatizações de empresas estatais (NETTO, 2012).

Em relação aos países de economia dependente, depois da experiência chilena, cumpre destacar o caso brasileiro. Com um pouco de atraso em relação aos países avançado, o que é típico dessas formações econômicas, o neoliberalismo se instalou, com maior robustez, na década de 1990. Por ocasião do governo de Fernando Collor de Mello (1990-1992), os primeiros passos foram dados, nesse momento, com foco no controle da inflação, mas a partir do uso indiscriminado da importação como mecanismo de regulação dos preços. Para Behring (2003), essa prática resultou em desfavorecimento do mercado interno, gerando um grande déficit na balança comercial e, consequentemente, a explosão da dívida pública, com todas as restrições para as políticas sociais que lhe são corolárias.

Não de forma homogênea, o avanço dessa forma de articulação entre Estado e economia avançou em diversos países até os dias de hoje, tendo na hipertrofia da esfera financeira 
uma suposta força sustentadora ante a queda tendencial da taxa de lucros, embora tal sustentação se dê mediante a mera especulação de capital fictício. Também é preciso destacar que há diferenças entre os vários governos à frente de cada nação, com implementação de medidas mais ou menos acirradas no horizonte neoliberal, mas com maior intensidade nas economias dependentes, sempre inseridas de forma desfavorável na dinâmica internacional, emulada pelo neoliberalismo, em especial pelo mecanismo da dívida pública.

O resultado mais eminente desse processo se dá na redução do alcance das políticas sociais públicas, com expressões visíveis nos serviços de educação, saúde, previdência etc., assim como nos níveis de desemprego e desigualdade (dentro de cada país, mas também entre os países ricos e pobres, cada vez mais distantes entre si). Esse ponto é fundamental para entender a capacidade de mitigação da pandemia por parte dos vários governos.

\section{A PANDEMIA DE COVID-19: PONTO DE EMINÊNCIA DAS ATUAIS CONTRADIÇÕES DO ESTADO}

A pandemia não pode ser entendida como um mero fenômeno de origem biológica, mas como uma expressão da conformação contemporânea do capitalismo e seu estilo de vida adjacente. O caráter de fácil propagação do vírus encontrou, no modo atual de vida, as condições potencializadoras ideais, tendo em vista o acelerado trânsito de pessoas por todo o mundo e, em especial, pela busca intensa dos interesses individuais. Esse caráter se expressa desde a negligência com as medidas protetivas por parte de sujeitos individualmente, até a tentativa de priorizar a economia em vez do rígido distanciamento social por parte de alguns governos nacionais, a exemplo da Itália, E.U.A. e Reino Unido no início da pandemia, ou do Brasil e México durante todo o seu curso (SOUZA, 2020a).

A nosso ver, a pandemia contribui para tornar ainda mais evidentes as contradições imanentes do sistema do capital, aqui apreendidas por meio de sua estrutura totalizadora de controle, o Estado. Em especial, tal caráter se mostra livre de disfarces no seu formato neoliberal, porquanto as contingências de acumulação em face da crise estrutural do capital (MÉSZÁROS, 2009), asfixie as políticas sociais públicas, limitando seu alcance e direcionando o Fundo Público dos Estados-Nação à dinâmica financeira da economia (BEHRING, 2003).

Nesse ponto se consubstancia a contradição estatal tornada evidente pela pandemia, uma vez que o seu enfrentamento demandou intervenções estatais que, a princípio, saem do lugar comum neoliberal. Primeiramente, o histórico do financiamento dos sistemas de saúde se mostrou decisivo na maior ou menor capacidade de contenção de novos casos, ou, sobretudo, em evitar a evolução dos casos graves até o óbito. Por exemplo, considerando a taxa de letalidade dos países europeus com mais casos ao final do quadrimestre em que experimentaram o auge da primeira onda da doença ${ }^{1}$, constatamos uma discrepância entre taxa de letalidade de Espanha, Itália e Reino Unido em relação à Alemanha. Ao mesmo tempo, observamos que os três primeiros países citados possuíam

\footnotetext{
${ }^{1}$ Calculamos essa taxa a partir de dados do Situation Report 101 (WORLD HEALTH ORGANIZATION, 2020), de 30 de abril de 2020. Usamos o quociente do número de óbitos pelo número de casos em cada país, expresso em porcentagem $(L=n$. óbitos $/ n$. de casos * 100).
} 
o menor financiamento público de saúde, tanto em porcentagem do Produto Interno Bruto (PIB) quanto per capita, ao passo que a Alemanha é o país de melhor desempenho nesse quesito, entre os quatro ${ }^{2}$. Elaboramos o Quadro 1 com esse comparativo, com a ressalva de que não se trata de nenhuma análise de significância estatística, mas apenas com intuito ilustrativo de possíveis relações entre financiamento prévio de saúde e a capacidade de enfrentar a COVID-19, naquele momento inicial, quando tudo era desconhecido e novo.

Quadro 1 Número de casos, óbitos, letalidade e investimento em saúde (per capita e \% do PIB) nos quatro países com mais casos de COVID-19 na Europa, jan. - abr. de 2020.

\begin{tabular}{|l|l|l|l|l|l|}
\hline País & Casos & Óbitos & Letalidade (\%) & Per capita & $\%$ do PIB \\
\hline Alemanha & 156.119 & 6.288 & 4 & 5.056 & 9,5 \\
\hline Reino Unido & 165.225 & 26.097 & 16 & 3.138 & 7,5 \\
\hline Itália & 203.591 & 27.682 & 14 & 2.545 & 6,5 \\
\hline Espanha & 212.917 & 24.275 & 11 & 2.341 & 6,2 \\
\hline
\end{tabular}

Fonte: Elaborado pelo autor com dados da World Health Organization (2020) e da OECD (2019).

Acreditamos que as comparações intercontinentais ainda são difíceis, porquanto os estágios da pandemia em cada continente não ocorreram concomitantemente, além de que os fatores regionais devem ser considerados. Porém, o caso europeu nos serve de exemplo para buscar análises ulteriores sobre a capacidade de sistemas públicos de saúde enfrentarem os problemas de saúde em geral e, sobretudo, em situações emergenciais como a da COVID-19. A comparação ilustrativa não pode ser tomada como cabal, uma vez que o cenário é muito complexo e envolve outros elementos, mas contribui para entender o porquê de Espanha e Itália terem se destacado negativamente quando da migração do epicentro da pandemia desde a China até a Europa.

A questão do financiamento público da saúde é uma das facetas mais contundentes de análise do comportamento neoliberal na dinâmica internacional. Silva e Mattos (2009) apresentam uma análise sobre o desmonte do Welfare State e a ascensão do neoliberalismo no pós-Segunda Guerra Mundial, tomando o caso do financiamento público da saúde como uma das mediações analíticas. Baseados em dados da OECD, os autores revelam que, no referido período, houve oscilação no financiamento, mas com algum crescimento devido, sobremodo, ao avanço da tecnologia em saúde e novas formas de tratamento, ambas mais dispendiosas. Tal constatação converge com a questão do crescimento do complexo médico-industrial/financeiro no mesmo período, entendendo esse complexo, conforme Vianna (2002), como o segmento do capitalismo contemporâneo que lucra a partir das doenças, inclusive por dentro dos sistemas públicos de saúde, quando esses consomem insumos farmacêuticos e tecnologia de saúde, ou ainda, devido à especulação financeira no setor privado, retroalimentado pela (e na) fragilização da esfera pública.

De acordo com os dados da OECD analisados por Silva e Mattos (2009), a média do financiamento público da saúde (em porcentagem do PIB) nos 15 países que compunham a União Europeia, na ocasião da adoção do euro como moeda (Alemanha, Bélgica, Espanha,

${ }^{2}$ Os dados são da Organization for Economics Cooperation and Development (OECD, 2019) e se referem a valores registrados em 2018. 
França, Irlanda, Itália, Luxemburgo, Holanda, Áustria, Portugal, Finlândia, Grécia, Reino Unido, Dinamarca e Suécia), foi de 6,6\% em 1995, subindo para 6,7\% em 1996, mas oscilando para menos a partir daí, até 6,4\% em 1998.

Procuramos atualizar a análise, incluindo, também, países de economia dependente. Nos dados da OECD (2019), são comparados 49 países 3 , quando se nota uma clara dicotomia entre países de capitalismo avançado e países de economia atrasada. Separamos, no Quadro 2, apenas os 10 países que mais investiram recursos públicos em saúde e os 10 que menos investiram (entre os 49 comparados).

Quadro 2 Financiamento público da saúde (\% do PIB): 10 países de maior financiamento e 10 países de menor financiamento entre 49 analisados pela OECD4.

\begin{tabular}{|c|c|c|}
\hline $\begin{array}{c}\text { Posição do país na } \\
\text { escala da OECD }\end{array}$ & País & $\begin{array}{c}\text { Financiamento público da } \\
\text { Saúde (\% do PIB) }\end{array}$ \\
\hline $1^{\circ}$ & E.U.A. & 14,3 \\
\hline 2 & Alemanha & 9,5 \\
\hline $3^{\circ}$ & França & 9,3 \\
\hline $4^{\circ}$ & Suécia & 9,3 \\
\hline $5^{\circ}$ & Japão & 9,2 \\
\hline $6^{\circ}$ & Dinamarca & 8,8 \\
\hline $7^{\circ}$ & Noruega & 8,7 \\
\hline $8^{\circ}$ & Holanda & 8,2 \\
\hline $9^{\circ}$ & Bélgica & 8,0 \\
\hline $10^{\circ}$ & Suiça & 7,8 \\
\hline 40 & Brasil & 4,0 \\
\hline $41^{\circ}$ & África do Sul & 3,5 \\
\hline $42^{\circ}$ & Letônia & 3,4 \\
\hline $43^{\circ}$ & Turquia & 3,3 \\
\hline $44^{\circ}$ & Rússia & 3,0 \\
\hline $45^{\circ}$ & China & 2,9 \\
\hline $46^{\circ}$ & Chipre & 2,8 \\
\hline $47^{\circ}$ & México & 2,8 \\
\hline $48^{\circ}$ & Indonésia & 1,4 \\
\hline $49^{\circ}$ & Índia & 0,9 \\
\hline
\end{tabular}

Fonte: Elaborado pelo autor com dados da OECD (2019).

Constatamos que existe uma clara hierarquização do financiamento da saúde, demarcando aqueles que podem investir (países ricos) e aqueles que nem tanto (países pobres). Portanto, o neoliberalismo, enquanto mediação econômico-política do capitalismo contemporâneo se expressa não apenas limitando o financiamento público da saúde, mas gerando um abismo entre países avançados e atrasados. Trata-se de expressão da

\footnotetext{
3 Um comentário preliminar sobre isso, com ênfase para o caso brasileiro, pode ser encontrado em Souza (2020b).

${ }^{4}$ A maioria dos 20 países do gráfico tiveram o dado registrado em referência ao ano de 2018. Países cujo dado é de 2016: Brasil, África do Sul, China, Rússia, Indonésia e Índia. O financiamento de saúde do Chipre foi registrado de 2017.
} 
hierarquização internacional constituída no processo de mundialização do capital (CHESNAIS, 2001), corolário às respostas do capital à sua crise estrutural.

Segundo Mészáros (2009), o Estado, na função corretiva ante os defeitos estruturais do capital, atua tentando, também, conter a contradição entre circulação e produção do capital, porquanto, em termos gerais, o grande capital precisa eliminar fronteiras à sua circulação, o que colide com os interesses do capital nacional em cada país. A solução do capitalismo mundializado para equacionar essa contradição é criar uma hierarquização internacional entre os Estados-nação, no interior da qual se define os privilégios e os desfavorecimentos no balanço neoliberal do financiamento de políticas sociais públicas.

A disparidade em relação à capacidade de financiar políticas sociais públicas anteriormente à pandemia se estende ao curso da mesma, consoante os dados sobre os orçamentos implementados por diversos países no enfrentamento da COVID-19 (não só diretamente na saúde, mas em outras áreas que sofrem os efeitos da pandemia). O primeiro monitoramento desse investimento foi conduzido por Elgin, Basbug e Yalaman (apud BARRÍA, 2020) e, em divulgação preliminar de 10 de maio de $2020^{5}$, revelou-se que os países mais ricos conseguem investir uma proporção maior de seu PIB contra a pandemia.

Entre os países ricos, a média de financiamento implementado durante a pandemia (até 10 de maio) foi de 6,7\% do PIB, ao passo que, na América Latina, por exemplo, foi de 2,4\%. Em países como Japão, Luxemburgo e Bélgica, o percentual foi de aproximadamente $20 \%$, contrastando com El Salvador, México, Bolívia, República Dominicana, Uruguai, Equador e Costa Rica, com investimento em torno de 1\%. Na América do Sul, Peru e Brasil foram os que mais investiram, com $9 \%$ e $8 \%$ do PIB, respectivamente, mas ainda longe do principal financiamento da América do Norte, os E.U.A. com 13\% (BARRÍA, 2020) ${ }^{6}$.

Em levantamento feito ao final de 2020, o Bank of America Merryll Lynch (BofA), cujo parâmetro analítico levou em conta a soma dos estímulos fiscais e monetários em 97 nações, confirmou algumas discrepâncias entre países ricos e pobres. Entre os que mais gastaram em ações contra a pandemia, aparece o Japão, país que movimentou recursos equivalentes a $63,7 \%$ do seu PIB; ou a França, com gasto de $37,5 \%$ do PIB. No outro extremo há países como o Brasil, que mobilizou recursos da ordem de $11,2 \%$ do seu PIB, Turquia com 12\%. Destaca-se o caso brasileiro, pois mesmo sendo uma das maiores economias do mundo, ficou atrás de países de seu continente, a exemplo de Chile e Peru, que gastaram, respectivamente, 20,6\% e 19,6\% (KUPFER, 2020)7.

Cumpre salientar que alguns estudos vêm apontado a interferência negativa que as medidas de austeridade na saúde têm provocado, sobretudo a partir da crise de 2008. A Grécia foi um dos países que mais sentiram a austeridade gerada a partir dessa crise, reduzindo cerca de $10 \%$ do financiamento total em saúde (considerando a porcentagem do

\footnotetext{
${ }^{5}$ Entrevista concedida à BBC News.

${ }^{6}$ Ver, também, Souza (2020b).

7 Em outros rankings, com outras metodologias, o Brasil aparece bem-posicionado. É o caso da avaliação do Fundo Monetário Internacional, que leva em conta apenas os incentivos fiscais e ainda toma como base uma relação da dívida pública com o PIB. Nesse ranking, o incentivo fiscal global girou em torno de $14 \%$ do PIB mundial e o Brasil foi o sétimo a mais gastar, com $8 \%$ do seu PIB.
} 
PIB) entre 2008 e 2014, quando caiu de 9,8\% para 8,1\%. Ao mesmo tempo, constatou-se o aumento da incidência de tuberculose, depressão e suicídio, mortalidade por HIV, neoplasias tratáveis, todos os tipos de cirrose, distúrbios neurológicos, doença renal crônica e doenças cardiovasculares (TYROVOLAS; KASSEBAUM; STERGACHIS, 2018). Em 2017, o financiamento de saúde grego caiu ainda mais, registrando 8,04\% do PIB (World Bank, 2020), comportamento que, provavelmente, está relacionado ao fato de esse país possuir a maior dívida pública da Europa, com um valor que, em 2019, chegou a equivaler a 182\% do seu PIB (CENTRAL INTELLIGENCE AGENCY, 2019).

Uma questão que ganhou relevo com a pandemia de COVID-19 diz respeito à disponibilidade de recursos estruturais e humanos de saúde, porquanto haja relação dos óbitos com a disponibilidade de leitos de terapia intensiva, respiradores mecânicos e trabalhadores de saúde (EMANUEL et al., 2020; REMUZZI; REMUZZI, 2020). A oferta rápida e resolutiva de assistência hospitalar, portanto, é decisiva para o prognóstico dos casos graves. Com efeito, a disponibilidade desses recursos de saúde depende do patamar de financiamento da saúde em cada país e, consequentemente, da consistência e alcance dos seus sistemas públicos. Ainda que a alocação emergencial de novos recursos deva ocorrer, sendo urgentemente necessária, um histórico de defasagem não será simplesmente resolvido no curso da pandemia, sem maiores consequências.

Além disso, precisamos registrar que não se trata só do tamanho do financiamento, tendo em vista que em alguns países ele tem até que, discretamente, aumentado. Trata-se, também, da dinâmica qualitativa do financiamento, que pode estar, por exemplo, direcionado à retroalimentação da lógica neoliberal. Vejamos o caso do E.U.A., país com maior financiamento público de saúde (Quadro 2); porém, com uma dinâmica favorável aos seguros privados de saúde e, consequentemente, ao complexo médicoindustrial/financeiro. Costa (2013, p. 159) explica que "em finais do Século XX, a tendência era, claramente, para o desenvolvimento de hospitais privados com fins lucrativos, enquanto ao nível do financiamento proliferavam os seguros privados. O modelo contratual assentava no sistema de reembolso das despesas". Trata-se de um sistema de saúde prolixo, com vários subsistemas em seu interior, alguns de natureza pública e voltados aos mais pobres, idosos, crianças, indígenas ou militares; todavia, com sua tônica ditada pelos seguros privados que chegam a cobrir $63,5 \%$ da população (soma dos seguros ligados ao emprego e seguros individuais) (COSTA, 2013).

Até mesmo sistemas que possuem a premissa da universalidade da saúde são invadidos pela lógica neoliberal. Santos (2018) destaca que, no caso brasileiro, o SUS tem coexistido com a proliferação de seguros e planos privados de saúde, com toda uma lógica que os favorece:

Ao se analisar o Plano Plurianual (PPA) 2016-2019, o orçamento previsto para o Ministério da Saúde foi de R\$ 5.284.770.555; desse montante, R\$ 442.007.143 previstos para o fortalecimento do Sistema Único de Saúde. Já de acordo com o relatório demonstrativo de Gastos Tributários - PLOA 2017 - que apresenta os valores de renúncia por tributo e por modalidade de gasto -, o montante referente à isenção fiscal no Imposto de Renda Pessoa Jurídica para Entidades sem Fins Lucrativos - Filantrópicas no ano 2017 foi de $\mathrm{R} \$ 460.238 .738$. Pode-se perceber que esse valor supera o que foi destinado no PPA citado para o fortalecimento do SUS (SANTOS, 2018, p. 210). 
Com isso, o financiamento do SUS orbitou sempre aquém do pretendido, girando em torno de 3 a $4 \%$ do PIB (MENDES, 2013), sem contar que boa parte do fundo público é capturado por instituições privadas conveniadas ao SUS (na oferta de leitos, procedimentos de diagnóstico e tratamento) ou pela estratégia de privatização via Organizações Sociais da Saúde (OSS) (SANTOS, 2018).

Outro exemplo é o italiano, que também traz a universalidade em sua doutrina, mas que passou por um reordenamento no início dos anos de 1990, com a adoção dos tickets sanitários. "O Ticket Sanitario representa uma quota de participação direta dos cidadãos na despesa pública, como contrapartida para os cuidados de saúde prestados pelo Estado" (OLIVEIRA; DALLARI, 2016, p. 897). Com o pressuposto de equilibrar a esfera fiscal, esse mecanismo fragilizou o alcance e a qualidade do Servizio Sanitario Nazionale, ferindo o princípio da universalidade tal como é entendido na Saúde Coletiva de viés crítico.

O National Helath System, na Inglaterra, também se notabilizou pela ideia de universalidade, mas desde os anos de 1980 tem aumentado os mecanismos de copagamento e, inclusive, "[...] nesse período, o Reino Unido iniciou a terceirização de serviços não clínicos [...]" (FERREIRA; MENDES, 2018, p. 6), ou ainda, “[...] implementou parcerias público-privadas (PPPs) para o financiamento de estruturas hospitalares [...]" (FERREIRA; MENDES, 2018, p. 6), revelando a tendência geral de invasão da perspectiva neoliberal no bojo dos sistemas públicos.

O Reino Unido, assim como Brasil e Itália, mesmo com sistemas de saúde que defendem a universalidade, estão entre os que mais sofreram com a COVID-19 (WORLD HEALTH ORGANIZATION, 2020) ${ }^{8}$, questão que não pode deixar de ser analisada a partir do processo de desmonte que os sistemas desses países passaram, consoante apontamos aqui.

Seja pela derruição do financiamento, seja pela sua dinamização a favor do mercado financeiro, esteve em curso um movimento de limitação dos serviços públicos de saúde, o que, agora, contrasta com as medidas no curso da pandemia, em uma tentativa inócua de remediar o histórico de defasagem. Com isso, percebemos o Estado, na sua faceta neoliberal, operando em uma arena que não lhe é cotidiana, vide o emprego de recursos durante a pandemia em patamar maior que o habitualmente alocado na saúde e outras políticas. Contudo, essa contradição não pode ser vista como algo atípico à natureza do Estado, porquanto ele seja inerentemente contraditório, tal qual o modo de produção do qual ele é componente.

Nessa esteira argumentativa, portanto, não se pode taxar a intervenção estatal em face da pandemia como sendo o desmoronamento do neoliberalismo, mas, tão somente, como a explicitação de sua natureza contraditória. Conforme Mészáros (2009), o capitalismo contemporâneo ativa os limites absolutos do capital e, dessa forma, é factível que a faceta assumida pelo Estado nessa fase do sistema do capital seja aquela que leva as suas

\footnotetext{
${ }^{8}$ Obviamente, a condução do enfrentamento pelos governos atuais é fator decisivo no êxito ou na falta dele. No caso brasileiro, tem pesado o negacionismo da gravidade da pandemia, a campanha contra vacina e a falta de planejamento e coordenação por parte no Ministério da Saúde para a condução das ações contra a COVID-19. Essa questão atual requinta um histórico de desmonte das políticas sociais, constituindo uma trágica miscelânia.
} 
contradições às últimas consequências. Tomando o conjunto dos Estados-nação, a pandemia de COVID-19 comparece, até o momento, como o ponto de maior eminência desse processo histórico.

\section{CONSIDERAÇÕES FINAIS}

A nosso ver, o enfrentamento do caráter de classe do Estado deve ocorrer desde as suas raízes e não apenas na questão isolada do financiamento das políticas sociais. Contudo, resistir aos desmontes dos serviços públicos e, no caso aqui enfatizado, da saúde pública, consiste em mediação importante para a luta de classes.

Não queremos, com isso, fortalecer as teses reformistas que defendem a superação do capitalismo por meio do acúmulo de políticas sociais cada vez mais fortes e amplas, mas apenas destacar que, considerando a temporalidade imediata, possui importância a tensão por intervenções que garantam alguma saúde aos trabalhadores e os mantenham vivos. A luta de classes precisa ser, também, luta por saúde, desde que não se desvie do horizonte revolucionário.

A pandemia de COVID-19 consubstancia o entrelaçamento das contradições estruturais do capital, seja na esfera social em geral, seja na esfera estatal, fazendo-as transbordar violentamente. Seus efeitos não devem deixar dúvidas sobre a necessidade de transformar, radicalmente, a base societária, o que inclui o Estado e as respostas dadas aos problemas sociais.

\section{REFERÊNCIAS}

BARRÍA, C. Coronavírus: os 10 países que mais gastaram para enfrentar a pandemia de COVID-19. BBC News, 2020. Disponível em:

https://www.bbc.com/portuguese/internacional-52721417. Acesso em: 10 set. 2020.

BEHRING, E. R. Brasil em Contrareforma: desestruturação do Estado e perda de direitos. São Paulo: Cortez, 2003.

CENTRAL INTELLIGENCE AGENCY. The World FactBook. CIA: Langley, 2019. Disponível em: https://www.cia.gov/library/publications/the-world-factbook/. Acesso em: 28 dez. 2020.

CHESNAIS, F. Mundialização: o capital financeiro no comando. Revista Outubro, v. 5, p. 728, 2001.

COSTA, J. P. A Reforma Obama e o sistema de saúde dos EUA. Arquivos de Medicina, São Paulo, v. 27, n. 4, p. 158-167, 2013.

EMANUEL, E. J.; UPSHUR, R.; THOME, B.; PARKER, M.; GLICKMAN, A.; ZHANG, C. et al. Fair Allocation of Scarce Medical Resources in the Time of COVID-19. New England Journal of Medicine, Massachusetts, n. 382, p. 2049-2055, 2020. 
ENGELS, F. A origem da família, da propriedade privada e do Estado. São Paulo: Expressão Popular, 2010.

FERRERIA, M. R. J.; MENDES, A. N. Reformas nos sistemas de saúde alemão, francês e britânico. Revista Brasileira em Promoção da Saúde, Fortaleza, v. 31, n. 4, p. 1-10, 2018.

GRAMSCI, A. Cadernos do cárcere. 5. ed. v. 3. Rio de Janeiro: Civilização Brasileira, 2012.

KUPFER, J. P. Brasil gastou pouco com a pandemia, na comparação com outros países. Coluna Economia UOL, 2020. Disponível em: https://economia.uol.com.br/colunas/josepaulo-kupfer/2020/12/22/brasil-gastou-pouco-com-a-pandemia-na-comparacao-comoutros-paises.htm?cmpid=copiaecola. Acesso em: 28 dez. 2020.

LOCKE, J. Segundo tratado sobre o governo. Ensaio acerca do entendimento humano. 2. ed. São Paulo: Abril Cultural, 1978.

MANDEL, E. O capitalismo tardio. São Paulo: Nova Cultural, 1982.

MARX, K. O Capital: crítica da economia política. Livro primeiro, Tomo I. 3. ed. São Paulo: Nova Cultural, 1988

MARX, K.; ENGELS, F. Manifesto do partido comunista. 2. ed. 5. reimp. São Paulo: Editora Martin Claret Ltda., 2010.

MENDES, A. A longa batalha pelo financiamento do SUS. Saúde e Sociedade, São Paulo, v. 22, n. 4, p. 987-993, 2013.

MÉSZÁROS, I. Para além do Capital: rumo a uma teoria da transição. 1. ed. 3. reimp. São Paulo: Boitempo Editorial, 2009.

NETTO, J. P. Crise do socialismo e ofensiva neoliberal. 5. ed. São Paulo: Cortez, 2012.

OLIVEIRA, A. M. C.; DALLARI, S. G. Reflexões sobre o Sistema Único de Saúde e o Servizio Sanitario Nazionale: a reforma da reforma - a adoção do Ticket Sanitario. Saúde e Sociedade, São Paulo, v.25, n.4, p.895-901, 2016

ORGANIZATION FOR ECONOMIC COOPERATION AND DEVELOPMENT. Health at a Glance 2019: OECD Indicators. OCDEiLibrary, 2019. Disponível em: https://www.oecdilibrary.org/sites/4dd50cog-en/1/3/9/3/index.html?itemld=/content/publication/4dd50cogen\&mimeType $=$ text $/ \mathrm{html} \&$ csp_=82587932df7co6a6a3fgdab95304095d\&itemIGO=oecd \&itemContentType=book. Acesso em: 27 dez. 2020.

REMUZZI, A.; REMUZZI, G. COVID-19 and Italy: what next?. The Lancet, London, v. 395, p. 1225-1228, 2020. 
SILVA, L. M. O; MATTOS, F. A. M. Welfare State e emprego em saúde nos países avançados desde o pós-Segunda Guerra Mundial. Revista de Economia Política, São Paulo, v. 29, n. 3, p. 135-152, 2009.

SMITH, A. A riqueza das nações. Volume I. São Paulo: Nova Cultural, 1988.

SANTOS, V. M. A captura do fundo público na política de saúde: o fortalecimento do setor privado. Argumentum, Vitória, v. 10, n. 3, p. 203-216, 2018. Disponível e:

https://periodicos.ufes.br/argumentum/article/view/18682. Acesso em 27 dez. 2020.

SOUZA, D. O. A pandemia de COVID-19 para além das Ciências da Saúde: reflexões sobre sua determinação social. Ciência \& Saúde Coletiva, Rio de janeiro, v. 25, supl. 1, p. 24692477, 2020 .

SOUZA, D. O. O subfinanciamento do Sistema Único de Saúde e seus rebatimentos no enfrentamento da COVID-19. PHYSIS: Revista de Saúde Coletiva, Rio de Janeiro: Instituto de Medicina Social da Universidade do Estado do Rio de Janeiro v. 30, n. 3, e300313, 2020b. Disponível em; https://www.ims.uerj.br/wp-content/uploads/2020/07/Revistaphysis-30-3_artigo-13.pdf. Acesso em: 26 dez. 2020.

TEIXEIRA, J. S. F. O neoliberalismo em debate. In: TEIXEIRA, J. S. F.; ALVES, G.; NETO, J. M.; OLIVEIRA, M. A. Neoliberalismo e reestruturação produtiva: as novas determinações do mundo do trabalho. 2. ed. São Paulo: Cortez, 1998.

TYROVOLAS, S.; KASSEBAUM, N.J.; STERGACHIS, A. The burden of disease in Greece, health loss, risk factors, and health financing, 2000-16: an analysis of the Global Burden of Disease Study 2016. The Lancet Public Health, v. 8, n. 3, p. 395-406, 2018.

VIANNA, C. estruturas do sistema de saúde: do complexo médico-industrial ao médicofinanceiro. PHYSIS: Revista de Saúde Coletiva, Rio de Janeiro: Instituto de Medicina Social da Universidade do Estado do Rio de Janeiro, v.12, n.2, p.375-390, 2002.

WORLD HEALTH ORGANIZATION. Coronavirus disease 2019 (COVID-19). Situation Report. 101. Genebra: WHO, 2020. Disponível em: https://www.who.int/docs/default-

source/coronaviruse/situation-reports/20200430-sitrep-101-COVID-

19.pdf?sfvrsn=2ba4e093_2. Acesso em: 26 dez. 2020.

WORLD BANK GROUP. Data World Bank, 2020. Disponível em:

https://data.worldbank.org/indicator/SH.MED.NUMW.P3. Acesso em: 27 dez. 2020.

\footnotetext{
Diego de Oliveira Souza

Enfermeiro formado pela Universidade Federal de Alagoas (Ufal), especialista em Saúde do Trabalhador pela Fatec Internacional, mestre e doutor em Serviço Social pela Ufal e pela Universidade do Estado do Rio de Janeiro (Uerj), respectivamente. Desde 2010 é professor da Ufal - campus Arapiraca, na graduação em Enfermagem. Desde 2018 é professor do Programa de Pós-Graduação em Serviço Social (PPGSS) da Ufal. Desde 2020 é professor do Programa de Pós-Graduação em Ensino e Formação de Professores (PPGEFOP) da Ufal - campus Arapiraca. É vice-líder do Grupo de Estudo Trabalho, Ser Social e Enfermagem (Getsse), cadastrado no CNPq desde 2014. Pesquisa sobre a relação trabalho-saúde, saúde do trabalhador, saúde coletiva e ensino em saúde, com livros e artigos publicados sobre os referidos assuntos.
}

Temporalis, Brasília (DF), ano 21, n. 41, p. 190-204, jan./jun. 2021. | ISSN 2238-1856 